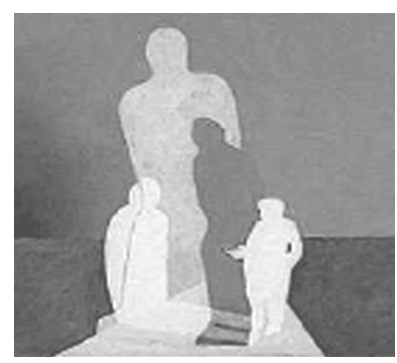

\title{
O poder e as injustiças nas pesquisas em seres humanos
}

William Saad Hossne

HOSSNE, W. S. The power and the injustices of research involving human beings, Interface - Comunic, Saúde, Educ, v.7, n.12, p.55-70, 2003.

Following general comments on the ethics of research involving human beings, this article focuses on the possibility of injustices occurring under the patronage of several forms of power. Concrete situations are used as examples. The analysis of possible injustices in the lights of Bioethics is emphasized, with multi- and trans-disciplinarity being highlighted. The author positions himself vis à vis the current characteristics of Bioethics. These are the views that led to the preparation of the Ethical Guidelines for research involving humans in Brazil (Resolution 196/96 and complementary documents issued by the National Council on Health). The systematics of the work done by the Executive Work Group - EWG appointed by the National Council on Health (the bureau for social control in the area of healthcare) in order to prepare the Guidelines is described. The participation of the several segments of society is highlighted, evidencing multi- and trans-disciplinarity, under the coordination of the EWG, which was chaired by the author. The main topics of the Brazilian Guidelines are discussed, focusing on their relation with the subject of power and injustice. The role of the Ethics in Research Committees (ERC) is stressed, as is the role of the National Commission for Ethics in Research - NCER.

KEY WORDS: Bioethics; clinical trials; guidelines.

Após considerações gerais sobre a ética na pesquisa envolvendo seres humanos, focaliza-se a possibilidade de ocorrências de injustiças, sob a égide de diversas formas de poder. Exemplificam-se situações concretas. Enfatizase a análise das possíveis injustiças à luz da Bioética, com destaque para multi e transdisciplinaridade. $\mathrm{O}$ autor se posiciona quanto às características atuais da Bioética, cuja ótica levou à elaboração das Diretrizes éticas para a pesquisa envolvendo seres humanos, no Brasil (Resolução 196/96 e complementares do Conselho Nacional de Saúde). Descreve-se a sistemática das atividades do Grupo Executivo de Trabalho - GET, designado pelo Conselho Nacional de Saúde (órgão de controle social na área da saúde), para elaborar as Diretrizes. É dado destaque à participação dos diversos segmentos da sociedade, evidenciando multi e transdiciplinaridade, sob a coordenação do GET, do qual o autor foi Presidente. Comentam-se os principais tópicos das Diretrizes brasileiras, enfocandose a sua relação com o tema de poder e injustiça. Salienta-se o papel dos Comitês de Ética em Pesquisa - CEP $e$ da Comissão Nacional de Ética em Pesquisa - CONEP.

PALAVRAS-CHAVE: Bioética; ensaios clínicos; diretrizes.

${ }^{1}$ Professor Emérito da Faculdade de Medicina de Botucatu, Universidade Estadual Paulista/Unesp; Coordenador da Comissão Nacional de Ética em Pesquisa - CONEP/MS. <cem@fmb.unesp.br> 
HOSSNE, W. S.

Ulisses - não temes o exército dos Aqueus?

Neoptolomeu - com a justiça do meu lado não temo a tua ameaça. Nem mesmo a tua violência me forçará a obedecer.

(Sófocles, 1988, p.98)

O que distingue o ser humano dos demais animais? Intelectuais de várias áreas, da Anatomia à Teologia e à Psicologia, buscam a resposta; quase sempre à base de categorização de características, sem estabelecer, porém, o elemento definidor da linha divisória.

O mais próximo que se tem chegado baseia-se em chistes: o ser humano é o animal que ri às gargalhadas quando seu semelhante sofre uma queda.

Creio que a melhor resposta até agora aventada parte de uma obra de ficção, de Vercors (Les animaux Dénaturés).

Homem e demais animais vivem e igualmente fazem parte de Natureza, com uma diferença: o Homem, diante da natureza, faz perguntas, o animal $e$ a natureza formam um - o Homem e a natureza formam dois.

$\mathrm{O}$ animal que, diante de qualquer fenômeno da natureza, fez a primeira pergunta, teria adquirido a condição de ser humano.

Ora, fazer perguntas é característica essencial do "filósofo". O ser humano nasce "filósofo".

Fazer a pergunta não é, porém, suficiente para o ser humano. A primeira pergunta gerou a primeira angústia: a angústia da resposta.

Buscar resposta a perguntas é próprio do pesquisador. Assim, o ser humano, à condição de "filósofo", agregou a de pesquisador.

Formular perguntas à natureza e buscar respostas, inevitavelmente, leva à necessidade de reconhecer a existência do "Outro", isto é, ao relacionamento humano; aí, também, inevitavelmente aflora a noção, por mais rudimentar que seja, de valores humanos.

Reconhecer o "Outro", estabelecer relacionamento, tomar noção da existência de valores, é próprio da Ética. Diziam os gregos, há quase trinta séculos, que o Homem é um ser Político; podemos dizer que ele é também originariamente um ser Ético, ao adquirir a condição de ser humano.

Enquanto reflexão e juízo crítico sobre valores, a Ética faz cada vez mais perguntas, o que leva alguns "pesquisadores pragmáticos" a dizer que a Ética mais pergunta do que responde. É verdade; contudo, sem as perguntas e indagações da Ética, não se chega à melhor resposta.

Este é o papel da Ética: fazer indagações e perguntas e estabelecer reflexões para permitir a
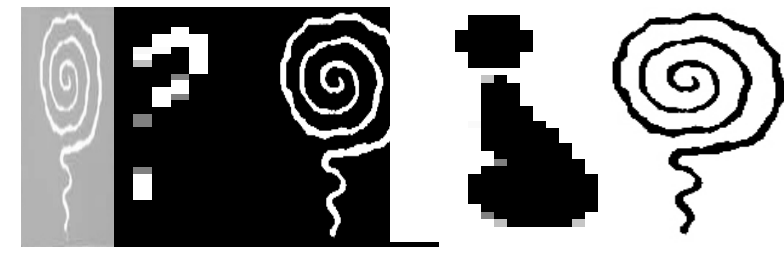
obtenção da resposta adequada.

E a resposta implica opção. Fazer opção pode ser tão angustiante a ponto de o ser humano chegar ao paradoxo de, em determinadas situações, preferir que não haja opção, ao invés de ter a oportunidade de fazê-la; o mais das vezes, a angústia o leva a desejar, inclusive, que a opção, que lhe cabe, seja feita por outrem. 
De qualquer modo, a Ética cria as condições para o opção entre valores, sendo indispensável existir uma condição de "valor" absoluto: Liberdade. Liberdade para que? Para a opção, com a devida responsabilidade.

Onde não há liberdade não há como se falar em Ética.

Enquanto juízo crítico de valores, a Ética exige, em nome da liberdade, o preenchimento de algumas condições para o seu exercício: o despojamento, tanto quanto humanamente possível, de preconceitos, ao lado da não coação $e$ da coerção, de qualquer tipo, quer exercida ou praticada.

Exige o exercício ético mais duas condições: humildade para respeitar a opinião, o juízo e a pessoa do outro e a grandeza para mudar a opção, caso se evidencie que a mesma não era a mais adequada.

Liberdade, não preconceito, não coação, não coerção, humildade e grandeza são, pois, exigências da Ética. Ora, liberdade e justiça estão intrinsicamente imbricadas.

A justiça, como preceito e fundamento ético, já nasceu com a própria filosofia.

Sofistas (auto-proclamados sábios) e filósofos (amigos da sabedoria) embora de modos às vezes diversos, proclamaram a justiça como elemento essencial nas relações humanas - e não obstante, a falta de justiça, a injustiça, continua muito presente nas relações entre seres humanos, aliás, entre seres humanos $e$ outros seres vivos.

Platão, na República, ao falar da tirania, afirma: os homens censuram a injustiça por medo de serem vítimas dela, não de cometê-la.

No campo da pesquisa em seres humanos, a Ética, e agora a Bioética, defende o referencial da justiça (alguns preferem falar em princípio) como um dos elementos indispensáveis.

A Encyclopedia of Bioethics (1978, p.802-10) registra, no verbete justiça:

Ações que estão erradas de um modo especial chamadas injustas e, provavelmente provocam aquele tipo especial de indignação associada com injustiça percebida que são de três formas básicas: primeira, discriminação odiosa ou o tratamento arbitrário desigual na legislação, na administração ou ditamento de regras ou na distribuição de tarefas ou benefícios; segunda, a exploração, isto é, tirar vantagem da confiança ou deficiência natural de outros para se ter ganhos injustamente às suas custas, ou colocar o outro em desvantagem injusta em situações de competições ou cooperações; e terceira, a injustiça jurídica que consiste em fazer julgamentos desrespeitosos sobre outras pessoas em suas tarefas, afirmações que não são justas para as pessoas.

A terceira tem muito pouca aplicação à Bioética. A segunda se aplica a métodos de aquisição e venda de sangue ou órgãos, bem como aos experimentos que tiram vantagem de pessoas pobres. A categoria de interesse filosófico mais profundo, no entanto, é a primeira $e$ especialmente àquelas ações nas quais há o alocamento de serviços médicos e suprimentos de remédios e equipamentos (justiça distributiva). (tradução livre) 
HOSSNE, W. S.

A questão da justiça distributiva assumiu relevância maior nos últimos quarenta anos, quando se tornou imperativa a discussão quanto à alocação de recursos para a Saúde Pública (Rawls, 1975; Daniels, 1985; Gracia, 1990).

Acrescentaria, também, como injustiça, a "estigmatização", embora se possa induzir que ela esteja incluída no primeiro tipo de injustiça, já referido.

Incluiria, ao lado do "julgdgmental injustice" todo e qualquer tipo de fraude, desde omissão proposital de informações ao sujeito da pesquisa até o falseamento de resultados. Enfim, a desonestidade de atos e/ou de propósitos ou intenções é também injustiça. Não é por outra

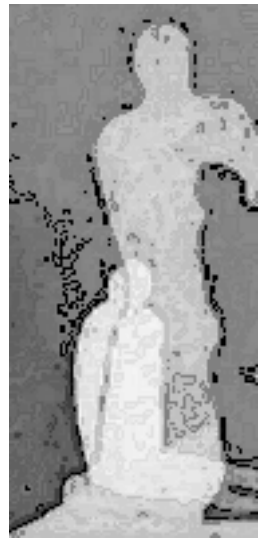
razão que Sócrates já dizia há 26 séculos que o importante na vida é viver honestamente, isto é, não praticando injustiça ainda que em retribuição à injustiça recebida. Aí estão honestidade $e$ injustiça no mesmo bloco ético.

Qualquer que seja o grau de discriminação ou de exploração, explícito ou implícito, exposto ou camuflado, ele irá, obviamente, interferir com o referencial ético da autonomia, limitando ou coibindo a autodeterminação e, por conseqüência, levando à possibilidade de ocorrência de injustiças.

$O$ referencial da autonomia, corporificado no consentimento do sujeito da pesquisa, consolidou-se exatamente a partir da regulamentação das pesquisas em seres humanos.

Quando falamos de poder e injustiça, de qual poder estamos falando: Poder político ou de governo (Estado), poder econômico, poder da ciência ou do cientista, poder militar, poder de corrupção? Poder do rico sobre o pobre? Dos países desenvolvidos sobre os subdesenvolvidos?

Não importa - poder significa sempre interesses organizados que podem reprimir sentimentos e oportunidades de justiça.

o poder, dado seu componente coercitivo, pode implicar maior ou menor grau de restrição da liberdade de reflexão crítica podendo, dessa forma, atingir na sua base o exercício da Ética. Por isso, a Ética só pode interagir com o poder, jamais a ele se submeter. É a Ética, teoricamente, que deve balizar o poder.

Perdoem o jogo de palavras - mas só há um poder ideal - é o poder da Ética. Nas pesquisas com seres humanos, mais do que nunca e, talvez, mais do que em qualquer outra situação, deve prevalecer o Poder da Ética.

As injustiças já ocorridas e que provavelmente estão ocorrendo e, infelizmente, ainda poderão ocorrer, têm sido cometidas, não raras vezes, pelo poder e/ou em nome do poder, inclusive pelos poderes que teriam por função impedir a ocorrência das injustiças.

Sempre, quando e onde o poder, em nome do que quer que seja, sufocar a Ética, pode ocorrer injustiça, no sentido filosófico.

Nesse sentido, a peça teatral "Filoctetes", de Sófocles, parece-me ilustrativa.

Filoctetes, picado por uma cobra, no santuário de Crisé, com seus gritos de dor e com ferida fétida no pé, é abandonado por Ulisses e seus marinheiros na ilha deserta de Lemnós, durante dez anos.

De acordo com a profecia, a vitoria dos gregos sobre Tróia dependia, porém, do arco (e flechas) de Hércules, armas que estavam em poder de 
Filoctetes - o que obriga Ulisses a voltar a ilha de Lemnós.

Consciente da natural relutância de Filoctetes, em vista da não solidariedade e da deslealdade cometida, Ulisses orienta Neoptolomeu (filho de Aquiles, amigo de Filoctetes) a, com mentiras, obter o arco de Filoctetes.

Neoptolomeu, reconhecendo a injustiça atroz infringida a Filoctetes, se recusa a mentir e a seguir as determinações de ulisses.

Ulisses procura justificar seus atos insinuando estar agindo em nome do bem comum e ameaça Neoptolomeu: "- Não temes o exército dos Aqueus? Neoptolomeu a Ulisses: - Com a justiça do meu lado não temo a tua ameaça. Nem mesmo a tua violência me forçará a obedecer".

Filoctetes, Ulisses e Neoptolomeu são três figuras que corporificam altos problemas morais e sociais, e que se confrontam. Nesse confronto, assiste-se à vitória da justiça, prevalecendo contra todas as pressões, venham dos homens ou do poder (Sófocles, 1988).

Patrocinador (Sponsor), pesquisador, sujeito da pesquisa e poder. Quem encarna quem na peça de Sófocles?

Respondo à pergunta não sob forma de diagnóstico, mas de desejo.

Gostaria que o patrocinador se identificasse mais com Neoptolomeu e menos com Ulisses; que o pesquisador sempre se identificasse com Neoptolomeu; o sujeito não fosse injustiçado como Filoctetes; que o poder (o arco e a flecha) estivesse à disposição da ética, protegendo os direitos dos "filoctetes" da vida, sem o exílio e o abandono e sem a picada de cobra.

Mesmo porque, como dizia Anaximandro (pré-socrático), ao longo do tempo os opostos pagam entre si as injustiças reciprocamente cometidas.

Acresce, conforme Heráclito, que a justiça não significa apaziguamento: pelo contrário, o conflito é o pai de todas as coisas: de alguns faz homens, de alguns, escravos, de outros, pessoas livres.

Estamos falando da justiça como preceito ético e não como elemento jurídico. Na "Ética a Nicômaco", Aristóteles já dizia que há uma justiça em sentido estrito, jurídico, e outra em sentido mais geral que engloba a totalidade das normas morais e políticas; a justiça incluiria todas as virtudes.

Assim, a Ética não pode ser instrumentalizada (ou confundida) para qualquer tipo de ideologia ou de poder. Esse fenômeno pode levar, inclusive, a se cometer injustiça em nome da Ética na medida em que se procura dar "roupagem" ética ao poder, enquanto expressão de interesses organizados.

Desde os casos Tuskegee e Willowbrook (apud Vieira E Hossne, 1997) até o recente caso das pesquisas de HIV/AIDS na África, a literatura registra número relativamente grande de situações eticamente não sustentáveis.

Várias publicações vêm chamando a atenção para projetos de pesquisa conduzidos por países desenvolvidos e que não seriam realizados nos respectivos países de origem; a questão já extrapolou para a mídia leiga. Recentemente, o Washington Post (dezembro 2000) publicou uma série de artigos relatando situações concretas de injustiças (exploração) para com os sujeitos da pesquisa, sobretudo de países pobres (Kottow, 2002).

Revista conceituada (BMJ) dedicou um de seus editoriais ao assunto; seu autor (Wilmhurst, 1997, p.840), tomando por base várias situações descritas na literatura, chega a denominar o fenômeno de imperialismo científico, afirmando já no subtítulo: "Se não se beneficiarem das 
descobertas, as pessoas pobres dos países em desenvolvimento não deveriam ser usadas nas pesquisas".

Custos menores, maior facilidade em obter o consentimento, menor oportunidade de reivindicações legais (leia-se indenização), menor controle sobre as pesquisas, são alguns dos fatores invocados para o fenômeno do "imperialismo científico".

Vale lembrar os relatos ilustrativos que vêm sendo publicados por "Medical Lobby for Appropriate Marketing" (MaLAM) sobre introdução e comercialização de drogas em diversos países em desenvolvimento; vários produtos, retirados, por falta de segurança ou eficácia, nos países de origem continuam a ser comercializados nos países pobres.

Há referência, inclusive, à comercialização de produtos com indicações que não foram objeto de "clinical trial".

Afirma-se textualmente (Wilmshurst, 1997, p.840):

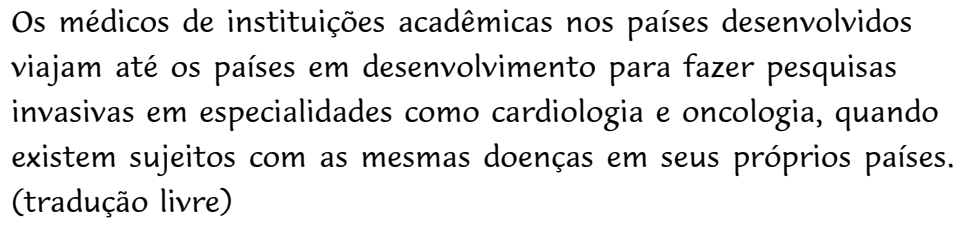

Trabalho recente (Kalb \& Koehler, 2002) com base em ampla revisão bibliográfica, analisa três grandes questões, frente ao "false claims act": o processo de buscar reembolso para os custos da pesquisa; o processo de realizar pesquisas clínicas; a potencial remuneração imprópria de pesquisadores ou de sujeitos da pesquisa.

As três questões abordam diferentes ângulos, inclusive o da justiça, sob o ponto de vista ético e também legal, evidenciando distorções concretas.

Tem sido amplamente discutida, sob o ângulo da justiça, a questão da disponibilidade do novo medicamento após o encerramento do projeto de pesquisa, sobretudo quando realizado em países em desenvolvimento (Cleaton-Jones, 1997); situações injustas vêm ocorrendo por falta de equacionamento eticamente adequado.

Tem sido apontada também a exploração de conhecimentos de países pobres em proveito de países desenvolvidos, como ocorre no caso de patentes. Cita-se, como exemplo, o ocorrido com o médico indiano Lemma, que teve como "colaboradores para publicação" pesquisadores de países desenvolvidos, os quais, na verdade não publicaram nada, mas simplesmente desenvolveram produto, depois patenteado, a partir do trabalho inicial do médico indiano, com "endod berry" para tratamento da esquistossomose (Mukergee, 1996).

A exploração pode também assumir outra feição. Em estudos multicêntricos, os pesquisadores de países em desenvolvimento não devem ser encarados como meros prestadores de serviços técnicos ou agenciadores de pacientes. Devem ter reconhecida sua capacidade de pesquisa. Por esta razão e sobretudo para evitar situações de injustiça com populações vulneráveis é importante a efetiva participação desses pesquisadores no planejamento e no delineamento do projeto de pesquisa. $\mathrm{O}$ envolvimento 
dos pesquisadores locais tem sido ressaltado (Kasper, 2002), porém, mais no sentido de assegurar o respeito aos valores culturais locais e para facilidade de obtenção do consentimento, esquecendo-se da participação acadêmica, criativa, intelectual.

As referências até aqui feitas exemplificam um tipo de interferência do poder (no caso dos países ricos).

Outros tipos de poder podem levar à injustiça. Por exemplo, o poder de "sedução" do pesquisador junto ao sujeito da pesquisa. Sedução ou astúcia que pode se utilizar da confiança da relação médico-paciente, "sedução" pela possibilidade de melhor atendimento (ou de mero atendimento); "sedução" pelo novo.

No livro "Histórias Apócrifas", Tchápek (2001, p.30) coloca na boca de Agaton (filósofo da época de Platão) as seguintes considerações que me parecem interessantes: "a astúcia é um dom, a racionalidade é uma qualidade, a sabedoria é uma virtude".

A astúcia é cruel e maliciosa, a racionalidade pode ser cruel para os homens mas pode ser justa diante de objetivos fixados - e a sabedoria não pode ser cruel, porque é benevolência e conduz à harmonia.

Alguns autores referem que a ética na pesquisa em seres humanos é diferente da ética na prática clínica. As obrigações do médico com seu paciente seriam diferentes daquelas do pesquisador com o sujeito da pesquisa. Contudo, não se deve esquecer que o pesquisador é o médico do paciente (sujeito da pesquisa) na maioria das vezes e, como tal, deve proteger o sujeito enquanto paciente.

De qualquer modo, é indispensável que o sujeito da pesquisa não seja coagido, de nenhum modo, e muito menos seduzido, na sua autodeterminação. Daí que as populações vulnerabilizadas ou dependentes devam ter mecanismos para proteção da sua efetiva autonomia - esse é um imperativo ético, comentado na literatura mas nem sempre concretizado nas normas.

$\mathrm{O}$ utilitarismo tem sido também utilizado, às vezes, como principio e até como forma de poder nas pesquisas em seres humanos. Chega-se a adjetivar a ética, como ética utilitarista ou utilitária. Com o devido respeito a Bentham e Stuart Mill, creio que se deva falar, nesses casos em procedimento, ou medida utilitária e não em ética; o utilitarismo, a meu ver, deve ser visto mais como doutrina moral do que ética, nessas situações.

O procedimento ou medida utilitária pode buscar fundamentos ou justificativas na Ética sem que esta seja despojada da sua característica natural de juízo crítico sobre valores e conflitos.

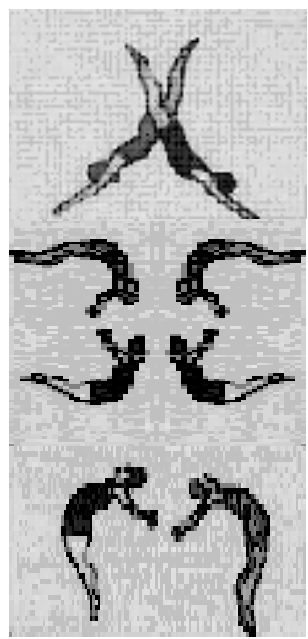

É óbvio que procedimentos utilitários podem ser eticamente aceitáveis ou eticamente inadequados. Afinal, sempre os fins justificariam os meios? É eticamente aceitável mentir ao sujeito da pesquisa para, em nome do utilitarismo, obter seu consentimento? Seria uma justiça ou uma injustiça? É a reflexão ética que deve responder.

Se o procedimento utilitário é muitas vezes aceitável eticamente, concordo com autores (Botbol, 2000, p.241, por exemplo) quando dizem "ética utilitária, vazia de uma noção profunda de justiça universal, 
encoraja a discriminação contra os pacientes economicamente vulneráveis em países em desenvolvimento" (tradução livre).

O poder (econômico em especial) pode também gerar injustiças resultantes de conflito de interesses; tem-se assinalado (e várias revistas científicas exigem) a necessidade de identificação de tais conflitos, tais como os resultantes de relação financeira com as empresas biomédicas, "tais como taxas de consultas, serviço de comissões de aconselhamento, possessão de igualdade, patentes de royalties, honorários para palestras, taxas para a opinião de experts e garantia de pesquisa" (Drazen \& Curfman, 2002, p.1901-2, tradução livre).

Há situações em que o pesquisador exerce um poder, em nome da Ética mas que, paradoxalmente, pode gerar injustiça.

Por exemplo, pessoas idosas, mulheres em idade fértil, gestantes, lactantes e crianças são, muitas vezes, aprioristicamente não incluídas em projetos de pesquisa, visando protegê-las, o que é louvável. Mas, a "proteção" não deve impedir a participação de pessoas desses grupos vulneráveis, se tal participação lhes for benéfica.

Outra situação paradoxal pode ocorrer quando se obtém a assinatura de termo de consentimento que não tenha sido formulado de maneira clara, devidamente esclarecido ao sujeito da pesquisa e/ou obtido de maneira não totalmente livre.

O termo de consentimento nem sempre tem recebido a atenção que merece; é, às vezes, encarado como mera peça burocrática, de "isenção de responsabilidades" e não como instrumento de natureza ética. Não raramente, o termo de consentimento é de tal complexidade que é ininteligível até para pesquisadores da mesma área embora não especialistas no campo específico da pesquisa proposta. O termo de consentimento deveria ser redigido pelo próprio pesquisador e assim explicado ao sujeito da pesquisa.

Corbie et al. (1999) mostram, em estudo realizado com African American, que os sujeitos da pesquisa consideravam a assinatura do documento como renúncia à sua autonomia e muito mais uma proteção legal para os médicos.

$O$ documento concretamente representativo da autonomia passa a ser documento em que, na verdade, o sujeito da pesquisa abre mão de sua autonomia - este paradoxo é uma injustiça.

Mesmo quando o termo de consentimento é apresentado sob forma acessível, tem-se demonstrado, em publicações internacionais e nacionais, que muitas vezes o sujeito da pesquisa o assinou sem saber exatamente o que the era proposto.

O sujeito da pesquisa, não raramente fragilizado, dependente direta ou indiretamente do pesquisador e ou da Instituição que o assiste, acaba abrindo mão de sua autodeterminação, concordando "in limine" com o que lhe é proposto. $O$ receio de ser prejudicado em seu atendimento (nas pesquisas na área da Saúde), desejo de ser agradável ao seu médico (por exemplo) e às vezes até mesmo "seduzido" pelo pesquisador, levam o sujeito da pesquisa a assinar o termo de consentimento.

Nessas circunstâncias, esvazia-se o significado do consentimento, agredindo-se o referencial da autonomia, (hoje tido por muitos como espinha dorsal da Bioética). E o mais grave, propicia-se, de modo sub-reptício, a 
"legalização" de eventuais injustiças já contidas na proposta. Questionado, o pesquisador dirá: "o sujeito da pesquisa concordou com a proposta - ele poderia ter-se recusado".

Pode até ser que, do ponto de vista meramente administrativo-legal, o argumento possa ser acolhido por aqueles que consideram a questão sob o ângulo legalístico. Cabe perguntar, porém, se eticamente (em nome da beneficência e da não maleficência) o pesquisador pode propor ao sujeito de pesquisa algo que é eticamente insustentável e que passaria a ser aceitável porque o sujeito concordou com proposta inaceitável?

Tem o pesquisador, eticamente, o direito de propor algo que sabidamente é inaceitável? E que se tornaria aceitável apenas porque haveria concordância do sujeito?

Desse modo, em nome de um referencial (ou princípio) caro à Bioética - a autonomia, comete-se uma injustiça dupla: injustiça de um ato não justo, imposto ao sujeito, de um lado, e injustiça da "validação" da injustiça por parte do sujeito da pesquisa (assinando o termo de consentimento), de outro lado.

É preciso lembrar que sempre existe um poder, maior ou menor, mais ou menos visível, do pesquisador sobre o sujeito da pesquisa, em vista da relação entre eles ser assimétrica; de um lado o dono do saber e de outro o dependente do saber e por ser dependente, fragilizado. Este poder, como qualquer outro, pode levar a injustiças, aparentemente minimizadas.

Na realidade, o pesquisador tem a responsabilidade de proceder à análise ética da proposta antes de submetê-la ao sujeito da pesquisa e, mais ainda, se convencido da adequação ética da proposta, atuar como parceiro do sujeito da pesquisa, fornecendo-lhe todos os dados para a devida avaliação, com liberdade de dar ou não seu consentimento.

Essa parceria está longe do "paternalismo" transposto do platonismo (República) para a relação pesquisador-sujeito da pesquisa.

Pelo preferencial da justiça, ônus, riscos e benefícios deveriam ser igualmente distribuídos. É justo que setores menos privilegiados economicamente arquem com os riscos e o mais privilegiados, apenas com os benefícios da pesquisa? É justo propor projetos de pesquisa, eticamente discutíveis, a determinadas populações porque elas são mais pobres, mais dependentes ou porque pertencem a países com "legislação" mais tolerante para eventuais conseqüências? O argumento de que tais populações assinaram o termo de consentimento sana a eventual injustiça?

Volto a questionar, uma proposta de pesquisa, eticamente inadequada ou questionável, torna-se eticamente adequada $e$ aceitável somente porque seres humanos, desprotegidos ou dependentes (até mesmo em termos de sobrevida) assinaram o termo de consentimento, chamado informado? A deficiência ética deixa de existir? Estamos falando de burocracia contratual ou de Bioética?

Na concepção Weberiana haveria dois tipos de ética: ética da conviç̧ão (agir conforme o dever sem maior consideração para com

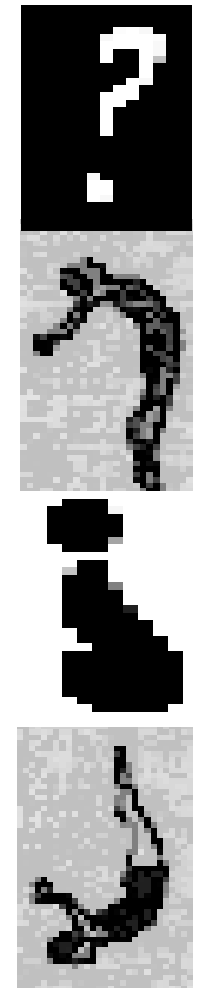


as conseqüências) e a ética da responsabilidade (toda ação deve ter em conta as conseqüências). A ética da responsabilidade seria própria do político; o intelectual seguiria, em geral, a ética da convicção.

Quando o poder, sobretudo o econômico e/ou aquele resultante da dependência, interfere a tal ponto com a ética na pesquisa em seres humanos, levando a injustiças, inclusive, sociais, podemos falar em Ética, seja da convicção ou da responsabilidade? Ou estamos cometendo uma heresia, chamando a situação de ética, no caso (paradoxo inaceitável) de "ética de conveniência"? E qualquer ética por mais "conveniente" que seja deixa de ser ética; pode-se até mesmo aceitar a situação, porém, com outro nome; jamais de ética.

Exemplo de "ética de conveniência" ocorre, por exemplo, quando se pretende submeter a ética à metodologia; eticamente falando, é a metodologia (que deve ser adequada) que se deve adaptar à ética.

Seriam expressão de "ética de conveniência", as mudanças e nuances de mudanças que se pretende introduzir na declaração de Helsinque?. Conveniência de quem? O Brasil, por meio do Conselho Nacional de Saúde e da Associação Médica Mundial, já se manifestou claramente contra tal mudança.

O tema deve ser analisado à luz da Bioética e, nos dias atuais, é indispensável procurar caracterizar o que cada um de nós entende por Bioética.

Há trinta anos, Bioética era um neologismo criado com o intuito de impedir o mau uso dos avanços da Biologia Molecular. Nesses trinta anos, assistiu-se e ainda se assiste, a um fenômeno curioso: nunca se falou tanto em Bioética como nos dias atuais e nunca se aplicou ao termo conotações tão diversas.

Vivenciamos um momento (que ainda persiste) em que Bioética foi entendida como uma nova ética médica, menos corporativa, com participação de não médicos. Assistimos, ao mesmo tempo, a um movimento que criou o Biodireito que, para alguns, seria a Bioética corporificada em disposições legais.

Alguns consideraram (e ainda há remanescentes) a Bioética como a Ética da Saúde, colocada em perspectivas sociais; chegaram, alguns (poucos, é verdade) a associar Bioética com Saúde Pública, como equivalentes.

Alguns críticos da Ética tentaram colocar um viés de ideologia - a Bioética seria a ética das minorias ou das maiorias para uns, ética da esquerda para outros.

De comum, porém, ocorreu aceitar-se que qualquer que fosse a concepção, a Bioética não se refere apenas aos problemas de fronteira da Biologia Molecular mas também aos problemas do dia a dia na área da vida.

O risco que se correu (e ainda se corre) é o do vedetismo, do modismo, da panacéia que pode levar ao esvaziamento de um dos fenômenos mais importantes nas relações humanas, ocorrido a partir da segunda metade do século passado, qual seja o desenvolvimento da Bioética.

Tanto isso é verdade que, em 1999, a literatura registra (Mimeteau E Israel, 1999) publicações assinadas por intelectuais (de fora da área biológica) que dizem ser a Bioética uma "impostura", um "embuste"; há 
mesmo filósofo (Folsheid apud Mimeteau \& Israel, 1999) que diz ser ela um "monstro", descrevendo-a como a "a quimera com asas como a da pomba e pele como a do rato". Seria a Bioética a Biologia da Ética ou a Ética da Biologia?, indaga o autor.

Ave por ave, prefiro o rouxinol, da fábula de Hesíodo, apesar do poder do falcão, pois ela é emblemática, como ponto de partida, para a cristalização da idéia do direito (Ergas, 800 a.C.).

Por essa razão, creio indispensável me situar, como fundador da Sociedade Brasileira de Bioética, conceitualmente quanto à Bioética.

Creio ser extremamente difícil, nos dias de hoje, perante o dinamismo do fenômeno, definir Bioética, mas considero possível e fundamental caracterizá-la. Bioética tem as seguintes características:

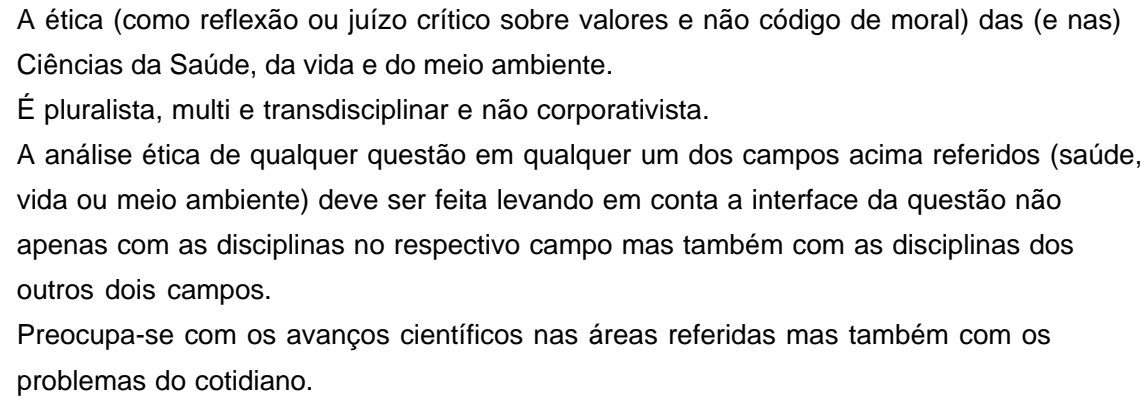

Assim me situando, passo a fazer alguns comentários sobre normas brasileiras referentes a ética na pesquisa em seres humanos.

A partir de 1996, o Brasil dispõe de normas específicas referentes à ética na pesquisa envolvendo seres humanos, em particular a Resolução 196/96 (Brasil, 1996).

A Resolução é de natureza essencialmente bioética, desde sua gênese, passando pelo seu conteúdo conceitual, até a operacionalização.

Para sua elaboração, o Conselho Nacional da Saúde designou Grupo de Trabalho multidisciplinar, pluralista, dentro da visão da Bioética, composto por 13 pessoas, com atuação em áreas diversas - médicos, enfermeiros, teólogos, engenheiros, industrial da área farmacêutica, odontólogo, representante de usuários do Sistema de Saúde.

Com base em dados dos Ministérios da Saúde, de Ciência e Tecnologia e da Educação, o grupo identificou cerca de trinta mil instituições universitárias, sociedades científicas, grupos de pesquisa, autoridades sanitárias, associações de portadores de deficiências etc. que, direta ou indiretamente, poderiam ter envolvimento com ética em pesquisa aos quais solicitou que enviassem sugestões para a elaboração da proposta.

Ao final de seis meses, com atividades de interação (palestras, reuniões, seminários), o Grupo de Trabalho analisou as sugestões e as contribuições.

Este material, aliado à análise de mais de uma centena de documentos $e$ normas de diferentes países e acrescido da análise da literatura referente

i ética em pesquisa, foi trabalhado, resultando em proposta preliminar de normas, discutida em audiências públicas no $1^{\circ}$ Congresso Brasileiro de Bioética (1995) e, finalmente, 
apresentada ao Conselho Nacional de Saúde e aprovada em outubro de 1996.

Considerou-se, de início, que alguns balizamentos na redação da Resolução deveriam ser definidos: transformar intenções em formulações adequadas; não criar disposições ambivalentes sem, porém, dar abrigo a posições maniqueístas; não tolher a liberdade de atuação, mas assegurar criação de mecanismos éticos de controle; criar condições de efetiva operacionalização com flexibilidade; não burocratizar, sem cair no vazio; criar condições para o efetivo exercício da Bioética; dentro dos preceitos da própria Bioética, criar interface adequada entre controle social e gestão; não estabelecer posições apriorísticas nem de proibição nem de total permissão e, finalmente, dar força legal às normas sem a rigidez das disposições legais.

A dinâmica de trabalho adotada visou obter respaldo dos diversos segmentos da sociedade, ao mesmo tempo que introduziu a própria discussão ética, sob o prisma da Bioética. Significa dizer que a Resolução 196/96 é de natureza bioética desde sua gênese; foi elaborada de modo absolutamente pluralista, livre de qualquer injunção corporativa.

A concepção, a estruturação e a consolidação da Resolução são também, essencialmente, de natureza bioética e mesmo a operacionalização das normas obedece a diretrizes de Bioética.

Assim, o referencial da justiça e sua inter-relação com o "poder", bem como com os demais referenciais da ética, são "tratados" à luz da Bioética, tal como descrito. Nesse sentido, creio que a Resolução 196/96 atende à quase totalidade das questões até aqui colocadas como pano de fundo do tema "poder e injustiças". Muitos dos pontos que têm sido levantados, aventados e/ou propostos na literatura estão concretamente estabelecidos na Resolução:

- ela não é cartorial, estatutária ou código, é um instrumento que obriga à análise bioética dos projetos de pesquisa. Sem ser lei, tem força legal, sem ser coercitiva, é consistente o suficiente para flexibilização com responsabilidade;

- dentro do referencial da justiça, a Resolução aplica-se não apenas às pesquisas biomédicas, mas a toda pesquisa envolvendo seres humanos que possa acarretar danos à dimensão física, psíquica, moral, intelectual, social, cultural ou espiritual do ser humano. Além disso, as normas se aplicam a toda e qualquer pesquisa, financiada, patrocinada, ou mesmo sem patrocínio, conduzida em ambientes institucionais públicos, privados ou não institucionais;

- tem suporte de disposições legais já existentes no país que lhe dão força legal, permitindo a análise ética pelo Ministério da Saúde (com as sanções que a lei permite), e o julgamento pelos órgãos profissionais de classe e pela justiça comum. (Brasil, 1996)

Cabe destacar, ainda, características operacionais da Resolução:

- todo e qualquer projeto deve ser analisado à luz da Resolução por Comitê de Ética de Pesquisa (CEP) essencialmente revestido de características bioéticas (não mais do que metade de seus membros pode pertencer à mesma categoria profissional, devendo participar homens e mulheres, profissionais de áreas diversas da saúde, filósofos, juristas, teólogos, sociólogos e, no mínimo, um representante dos sujeitos da pesquisa) ${ }^{2}$

- em respeito à autonomia, o sujeito da pesquisa deve ser esclarecido dos objetivos do trabalho e dar seu Consentimento, denominado Livre e Esclarecido (não apenas informado),

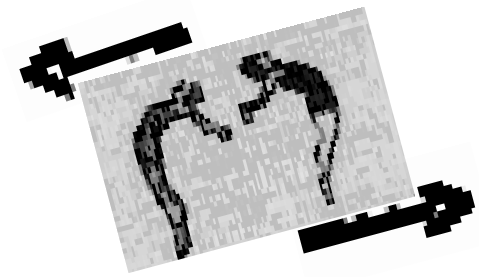

${ }^{2} \mathrm{O}$ CEP é um colegiado

interdisciplinar e

independente, com

"múnus público", de

caráter consultivo,

deliberativo e educativo, criado para defender os

interesses dos sujeitos da pesquisa em sua integridade e dignidade $e$ para contribuir no desenvolvimento da pesquisa dentro de padrões éticos. Ao aprovar projetos, passa a ser co-responsável pelos aspectos éticos envolvidos, não tendo

função meramente cartorial ou formal. Contudo, a responsabilidade será sempre do pesquisador que responde pelo projeto (com ou sem seguro) pois é indelegável e intransferível. Tem poder para interromper suspender ou cancelar projeto de pesquisa, bem como de solicitar, à instituição sede, a instauração de processo de sindicância. 
${ }^{3} \mathrm{O}$ sujeito da pesquisa fica com cópia do Termo de Consentimento, como peça de valor contratual para, dentro dos princípios da justiça, defender seus direitos perante a Justiça comum e os órgãos de classe. sem qualquer tipo de indução, sedução, coação ou coerção ${ }^{3}$;

- a Resolução assegura aos sujeitos da pesquisa livre acesso a todas as informações, bem como a liberdade de recusa, sem nenhum tipo de "penalização" ou restrição ao atendimento de suas necessidades;

- estabelece cuidados especiais para os grupos vulneráveis ou dependentes (qualquer tipo de dependência);

- assegura aos sujeitos direito à assistência de eventuais situações decorrentes da pesquisa e que jamais possa ser exigida renúncia ao direito de reivindicação de indenização e ou de ressarcimento;

- define que a atividade da pesquisa deve ter relevância social e resultar em vantagens significativas e minimização do ônus para os sujeitos vulneráveis, o que garante igual consideração dos interesses envolvidos, não perdendo o sentido de sua destinação sócio humanitária (justiça e eqüidade);

- assegura aos sujeitos da pesquisa os benefícios resultantes do projeto, seja em termos de retorno social, acesso aos procedimentos, produtos ou agentes da pesquisa, bem como condições de acompanhamento, tratamento ou de orientação, conforme o caso, nas pesquisas de rastreamento;

- atenta para que não ocorra conflito de interesses entre o pesquisador e os sujeitos da pesquisa ou patrocinador do projeto;

- orienta que sejam respeitados valores culturais, sociais, morais, religiosos e éticos dos sujeitos, bem como hábitos e costumes quando as pesquisas envolverem comunidades;

- define que haja retorno e proteção contra estigmatização e/ou discriminação para as comunidades envolvidas;

- define que o protocolo da pesquisa seja completo, com descrição da metodologia, justificativa ética para uso de placebo ou de wash-out; orçamento financeiro detalhado: recursos, fontes e destinação, forma e valor da remuneração do pesquisador;

- na pesquisa com novos fármacos, medicamentos, vacinas e testes diagnósticos, em qualquer ensaio clínico e, particularmente, nos conflitos de interesses da pesquisa com novos produtos, garante que a dignidade e o bem estar do sujeito prevaleçam sobre outros interesses;

- orienta que em estudos multicêntricos, na medida do possível, o pesquisador participe do delineamento do projeto antes de seu início;

- estabelece que o financiamento não esteja vinculado a pagamento per capita dos sujeitos efetivamente recrutados;

- assegura, por parte do patrocinador ou, na sua inexistência, por parte da instiuição, pesquisador ou promotor, acesso ao medicamento em teste, caso se comprove sua superioridade em relação ao tratamento convencional.

- na área temática especial "pesquisas coordenadas do exterior ou com participação estrangeira e pesquisas que envolvam remessa de material biológico para o exterior" determina que: os ônus e benefícios advindos do processo de investigação e dos resultados da pesquisa devem ser explicitados no protocolo e distribuídos de forma justa entre as partes envolvidas; seja emitido documento de aprovação por Comitê de Ética em Pesquisa ou equivalente da instituição do país de origem que promoverá ou também executará o projeto (quando não estiver previsto o desenvolvimento do projeto no país de origem, a justificativa deve ser colocada no protocolo para apreciação do CEP da instituição brasileira); seja elaborada declaração de uso de material biológico, dados e informações coletados (exclusivamente para os fins previstos no protocolo) para todos os que trabalham na pesquisa. (Brasil, 1996) 
HOSSNE, W. S.

Iniciei o texto com Sófocles, gostaria de terminá-lo com Hume e Brecht.

A natureza diz: Tolero vossa paixão pela ciência, mas fazei com que vossa ciência seja humana de tal modo que possa ter relação

direta com a ação $e$ a sociedade.

Sede um filósofo, mas no meio de toda vossa filosofia, sede sempre um homem.

(Hume)

Brecht, no poema "Aos que vivem depois de nós".

E, contudo sabemos que também o ódio contra a baixeza endurece as feições; que também a cólera contra a injustiça enrouquece a voz. Ah! os que quisemos preparar terreno para a bondade não pudemos ser bons. Vós, porém, quando chegar o momento em que o homem seja bom para o homem lembrai-vos de nós com indulgência.

O Brasil conta com 323 Comitês de Ética em Pesquisa institucionais (CEP) já registrados e mais 121 em tramitação, todos voltados para a proteção dos direitos dos sujeitos da pesquisa. São cerca de 4.200 pessoas, de diferentes formações, que se reúnem, pelo menos uma vez por mês, para analisar projetos de pesquisa envolvendo seres humanos. Coordenando o conjunto existe a Comissão Nacional de Ética de Pesquisa (CONEP), que atua como instância normativa, de recurso e de coordenação. A CONEP tem 13 membros que atuam em diferentes áreas (necessariamente um representante de usuário/sujeito da pesquisa), de modo transdisciplinar. Cabe à CONEP a aprovação final, após manifestação do CEP, dos projetos das áreas temáticas: genética humana, reprodução humana, pesquisa em povos indígenas, pesquisa com cooperação estrangeira, pesquisas que envolvem biosegurança, pesquisas com novos equipamentos e pesquisas com procedimentos - cuja aceitação ainda não está consagrada na literatura. É responsável, ainda, pela elaboração de normas complementares, específicas (Resolução 251/97; 292/99; 303/2000; 304/2000), bem como pela formação de um banco de dados sobre todos os projetos desenvolvidos no país. O sistema CONEP-CEP é interarticulado e harmônico. Os eventos adversos são imediatamente comunicados ao CEP e, em seguida, à CONEP, para análise em interface com a Agência Nacional de Vigilância Sanitária. 


\section{Referências}

BOTBOL, B.M. The shrinking of human rights: the controversial revision of the Helsinki Declaration. HIV Med., n.1, p.238-45, 2000.

BRASIL. Ministério da Saúde. Conselho Nacional de Saúde. Resolução 196/96, de 10 de outubro de 1996. Aprova diretrizes e normas regulamentadoras de pesquisa envolvendo seres humanos. Diário Oficial da União, Brasília, 16 out. 1996. Seção

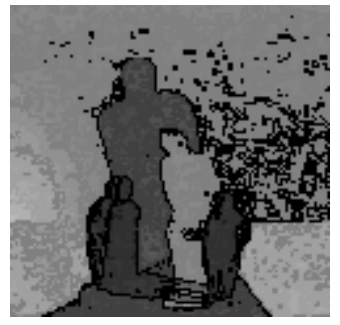
1, p.21082.

CLEATON-JONES, P.E. Availability of antiretraviral therapy after clinical trials with HIV infected patients are ended. BMJ, n.314, p.887-8, 1997.

CORBIE, G.S, THOMAS, S.B., WILLIAMS, M.V., MOODY, S.A. Attitudes and beliefs of African American toward participation in medical research. J. Gen. Int. Med., n.14, p.537-46, 1999.

DANIELS, N. Justice: health care. Cambridge: Univ. Press, 1985.

DRAZEN, J.M., CURFMAN, G.D. Financial association of authors. New Engl. J. Med., n.346, p.1901-2, 2002.

ENCYCLOPEDIA OF BIOETHICS. Nova York: Warren Reich, 1978.

GRACIA, D. Que és um sistema justo de servicios de salud? Princípios para la assignacion de recursos escasos: Bioética, temas y perspectivas. Washington: OPAS, 1990. p.187-201. (publicación científica, 527).

KALB, P.E., KOEHLER, K.G. Legal issues in scientific research. Jama, n.287, p.85-91, 2002.

KASPER, C.K. Conduct of clinical trials in developing countries. Haemophilia, n.8, p.166-9, 2002.

KOTTOW, M. Who is my brother's keeper? J . Med. Ethics, n.28, p.24-7, 2002.

MIMETEAU, G., ISRAEL, L. Le Mythe Bioéthique-Bassano. Paris: Bassano, 1999.

MUKERGEE, M. The berry and the parasite. Sci. Am., v.274, n.4, 1996.

RAWLS, J. Teoria de la justicia. Madrid: Fundo de Cultura econômica, 1975.

SÓFOCLES. Filoctetes. Trad. J. R. Ferreira. Coimbra: Inst. Nac. Invest. Científico, 1988.

TCHAPEK, K. Historias apócrifas. Trad. A. Jovanovic. Rio de Janeiro: Editora 34, 2001.

VIEIRA, S., HOSSNE, W. S. Experimentação com seres humanos. São Paulo: Moderna, 1997.

WILMSHURST, P. Scientific imperialism. BMJ, n.314, p.840-1, 1997.

HOSSNE, W. S. El poder y las injusticias en las pesquisas en seres humanos, , Interface Comunic, Saúde, Educ, v.7, n.12, p.55-70, 2003.

Posteriormente a las consideraciones generales sobre la ética en la pesquisa que involucra seres humanos, se enfoca la posibilidad de ocurrencias de injusticias, bajo la égida de diversas formas de poder. Se ejemplifican situaciones concretas. Se enfatiza el análisis de las posibles injusticias a la luz de la Bioética, destacando la multi y transdisciplinariedad. El autor se posiciona respecto a las características actuales de la Bioética, cuya óptica llevó a la elaboración de las Directrices éticas para la pesquisa que involucra seres humanos, en Brasil (Resolución 196/96 y complementarias del Consejo Nacional de Salud). Se describe la sistemática de las actividades del Grupo Ejecutivo de Trabajo - GET, designado por el Consejo Nacional de Salud (órgano de control social en el área de salud), para elaborar las Directrices. Se destaca la participación de los diversos segmentos de la sociedad, evidenciando multi y transdiciplinariedad, bajo la coordinación del GET, del cual el autor fue Presidente. Se comentan los principales tópicos de las Directrices brasileñas, enfocando su relación con el tema de poder e injusticia. Se resalta el papel de los Comités de Ética en Pesquisa - CEP y de la Comisión Nacional de Ética en Pesquisa - CONEP.

PALABRAS CLAVE: Bioética; ensayos clínicos; directrices. 
HOSSNE, W. S.

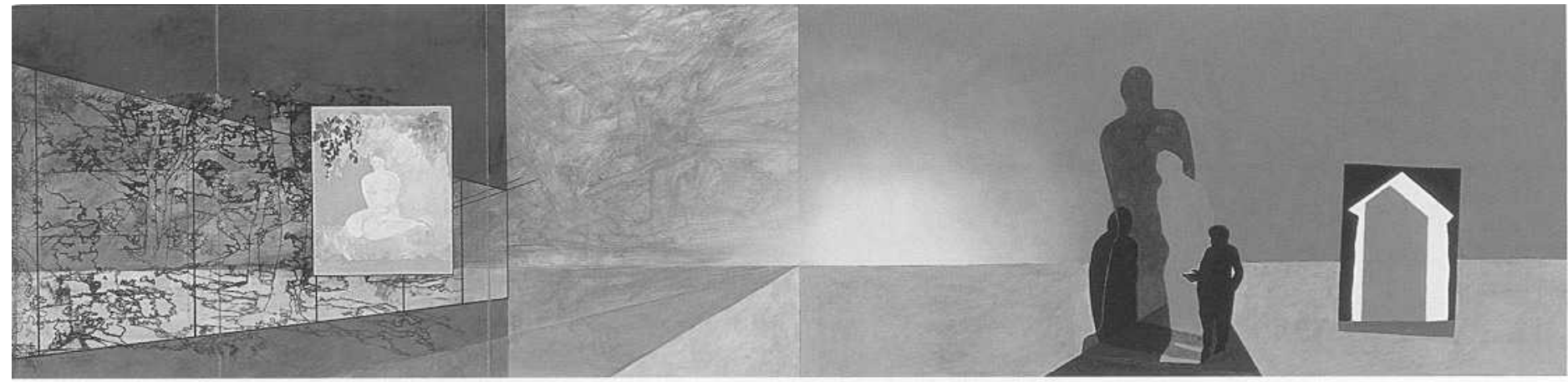

BARAVELLI, 0 argumento, São Paulo, 2000 